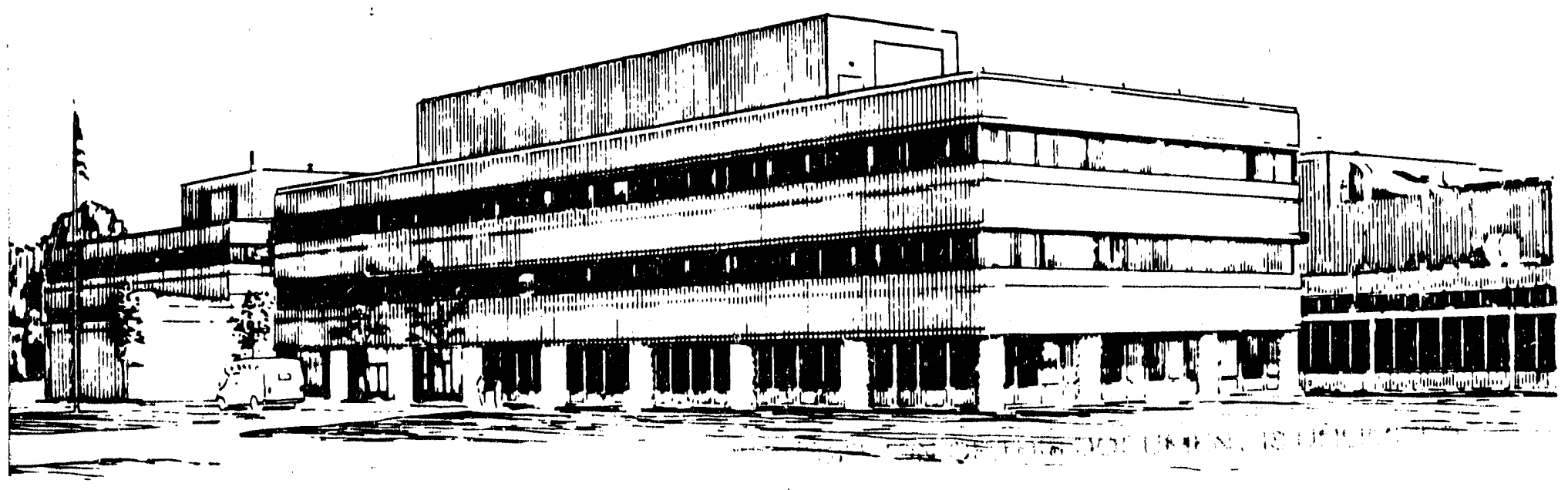




\section{NOTICE}

This report was prepared as an account of work sponsored by an agency of the United States Government. Neither the United States Government nor any agency thereof, nor any of their employees, makes any warranty, express or implied, or assumes any legal liability or responsibility for the accuracy, completeness, or usefulness of any information, apparatus, product, or process disclosed, or represents that its use would not infringe privately owned rights. Reference herein to any specific commercial produce, process, or service by trade name, trademark, manufacturer, or otherwise, does not necessarily constitute or imply its endorsemenc, recommendation, or favoring by the United States Government or any agency there of. The views and opinions of authors expressed herein do not necessarily state or reflect those of the United States Government or any agency thereot.

\section{NOTICE}

This report has been reproduced directly from the best available copy.

Available to DOE and DOE contractors from the:

Office of Scientific and Technical Information P.O. Box 62

Oak Ridge, TN 37831;

Prices available from (615) 576-8401.

Availabie to the public from the:

National Technical Information Service

U.S. Department oi Commerce

5285 Port Royal Road

Springfield, Virginia 22161

$703-487-4650$ 


\title{
A STARK-TUNED, FAR-INFRARED LASER FOR HIGH FREQUENCY PLASMA
} DIAGNOSTICS ${ }^{+}$

\author{
D. K. Mansfield, M. Vocaturo, L. Guttadora, \\ M. Rnckmore* and K. Micai ${ }^{* *}$ \\ Princeton University, Plasma Physics Laboratory \\ Princeton, N. J. 08543 \\ and \\ Peter A. Krug \\ School of Physics, University of Sydney \\ NSW, Australia 2006
}

PPPL- -2803

DE92 010004

\begin{abstract}
A Stark-tuned optically pumped far-infrared methanol laser operating at 119 micrometers has been built. The laser is designed to operate at high power while exhibiting a well-separated Stark doublet. At a pump power of 65 Watts and electric field of $1 \mathrm{kV} / \mathrm{cm}$ the laser has delivered over 100 $\mathrm{mW}$ c.w. while exhibiting a frequency splitting of $34 \mathrm{MHz}$. These parameters indicate that this laser would be suitable for use in the present generation of modulated interferometers on large thermonuclear plasma devices. The achieved modulation frequency is more than an order of magnitude higher than could be achieved using standard techniques.
\end{abstract}

Key words: Stark-tuned FIR laser, plasma diagnostics

* Present address: Pennsylvania State University, University Park,

Penna. 16802

** Present address: Hamilton High School West, Hamilton, N. J. 08610

*** Present address: Optical Fibre Technology centre, Univ. of Sydney, NSW 2006, Australia

+This work was supported under DoE contract \#DE-AC02-76-CHO3073. 


\section{INTRODUCTION}

At present, on large thermonuclear plasma devices, modulated far-infrared (FIR) laser interferometers are the most common diagnostic employed for measuring the electron density $[1,2]$. The modulation frequency is typically introduced into these interferometers either mechanically by a rotating grating or optically by mistuning the output frequencies of two independent FIR lasers and then mixing those two outputs together to obtain a beat signal. The maximum modulation frequency obtainable by the former method is typically limited to between $10 \mathrm{kHz}$ and $100 \mathrm{kHz}$ by mechanical considerations. The maximum beat frequency obtainable by the optical method is typically 1-3 MHz and is limited by the narrow gain bandwidth available in these types of lasers (FWHM $\approx 5-8 \mathrm{MHz}$, at low pump power).

In practice, a nagging problem associated with these low ( $\leq 1 \mathrm{MHz}$ ) modulation frequencies is that they result in the loss of fringe count during rapid changes in the plasma density. Such rapid changes typically occur on large plasma devices during the injection of solid pellets for fueling, during extreme cases of MHD activity and during major disruptions. In order to harden an interferometer against such problems it would be desirable to increase the modulation frequency significantly. This is because, at its most fundamental level, a modulated interferometric measurement is made by comparing the phase between two sinusoidal beat signals - the reference and scene signals:

$$
V_{\text {ref }}(t) \propto \cos (\Delta \omega t)
$$

and

$$
\mathrm{V}_{\text {scene }}(\mathrm{t}) \alpha \cos (\Delta \omega \mathrm{t}+\zeta(\mathrm{t}))
$$

Where $\Delta \omega$ is the modulation frequency and $\zeta(t)$ is the phase difference between the two signals which is impressed on $V_{\text {scene }}(t)$ by the passage through the plasma column of one of the laser beams generating the beat signal. That is:

$$
\zeta(\mathfrak{t}) \alpha \int \mathrm{n}(\mathrm{r}, \mathrm{t}) \mathrm{dl},
$$

where the integral of the plasma electron density $n(r, t)$ is taken along the path of the laser beam. When the rate of change of the line integrated density becomes so large as to be comparable to $\Delta \omega$, 
it is no longer possible to measure the phase difference between the two signals. Hence, to (') that a measurement can always be made, it is necessary that:

$$
|\partial \zeta(t) / \partial t| \ll \Delta \omega
$$

In order to ensure that (4) is fulfilled it is desirable to make $\Delta \omega$ as large as possible and certainly larger than $1 \mathrm{MHz}$.

In addition to the considerations given above, as a practical matter, the power levels needed to run a multi-channel interferometer on a large plasma device are typically several tens of milliwatts to several hundreds of milliwatts [2]. Therefore, any technique employed to enhance the modulation frequency must be viable at the highest achievable FIR power levels.

In this regard, Bionducci has demonstated that, at low pump power levels, the gain curve of the $119 \mu \mathrm{m}$ line of $\mathrm{CH}_{3} \mathrm{OH}$ breaks into two equivalent gain curves when the gain medium is immersed in a uniform electric field [3]. Further, the frequency difference between these two gain curves is simply proportional to the applied electric field. The $119 \mu \mathrm{m}$ line happens to be the most powerful c.w. line available in the FIR and is therefore widely used by the plasma physics community in the present generation of modulated interferometers $[1,2]$. In the work to be described, the Stark effect has been exploited in a $\mathrm{CH}_{3} \mathrm{OH}$ laser designed to be powerful enough to be used on a tokamak or other large plasma device while simultaneously capable of producing a very high modulation frequency.

\section{DESIGN AND CONSTRÜUTION}

The design of the FIR resonator tube is shown in Fig 1. The tube consists of a rectangular pyrex tr be with $2 \mathrm{~mm}$ thick walls and with inside dimensions of $22 \mathrm{~mm} \times 9.5 \mathrm{~mm}$. These particular dimensions have been demonstrated to be nearly optimal in order to avoid pump laser loss and resonances [3]. In order to apply a uniform electric field to the gain medium, the two large inside faces of the rectangular tube were coated with aluminum by a process described below. The rectangular tube is surrounded by a cylindrical pyrex water jacket. This design allows the entire structure to be water-cooled without fear of electrical beakdown or the need for an oil coolant. The enhancement of the FIR output power due to this kind of temperature control of the resonator walls has been described elsewhere [4].

The input coupler consists of a flat gold-coated copper mirror with a centered $4 \mathrm{inm}$ input coupling hole. A hybrid metal-dielectric mirror with a $6 \mathrm{~mm} \mathrm{Si}$ aperture is employed as the output 
coupler [5]. Water-cooling of the input and output couplers as well as of the resonator walls provides active thermal stabilization of the cavity. Passive thermal stabilization of the cavity structure is accomplished in the standard way with the use of four Super-Invar rods. Two versions of this resonator were constructed. The original version had a length of 1 meter while the later version had a length of 2 meters.

The grating-tuned $\mathrm{CO}_{2}$ pump laser delivered $70 \mathrm{Watts}$ on the $9 \mathrm{P}(36)$ line. This laser has also been described elsewhere [4]. The pump power is focussed into the FIR resonator by a ZnSe lens with a $75 \mathrm{~cm}$ focal length. The orientations of the pump and FIR polarizations are also indicated in Fig 1.

The irside of the rectangular tube was coated by evaporating a conducting film of aluminum onto the two large faces. The evaporation process involved pulling a movable tungsten filament along the length of the rectangular tube. The filament was preloaded with high purity aluminum. A shield which moved with the resistively heated filament prevented the two small faces of the tube from also being coated. The $1 \mu \mathrm{m}$ thickness of the film is much larger than the skin depth of aluminum at the laser operating frequency $(\approx 54 \mathrm{~nm})$. Hence, this film acted as a highly conducting waveguide wall. The DC electrical connections to the metalic film electrodes were made by simple mechanical contact.

\section{PERFORMANCE}

Figure 2 shows the cutput power of the 2 meter FIR resonator as a function of cavity length. The pyroelectric detector used in this scan was located about 2 meters from the output coupler. The absolute output power was determined with a calorimeter. With the use of a sheet of high sensitivity liquid crystal, the cavity modes shown in Fig 2 have been seen to couple efficiently to free space $\mathrm{TEM}_{00}$ modes. The laser output, when viewed with the liquid crystal, was clearly circularly symmetric. The extremely clean cavity mode structure shown in Fig. 2 is due to the low effective Fresnel number $(\approx 0.2)$ of the rectangular cavity. A somewhat more crowded mode structure was observed with the 1 meter cavity owing to a larger Fresnel number.

With the application of an intracavity electric field the gain curve is seen in Fig 3 to break into two distinct gain curves with the doublet separation linearly dependent on the electric field strength. However, it should be noted that the doublet separation $(\approx 35 \mathrm{MHz}$ ) achieved at $\approx 1 \mathrm{kV} / \mathrm{cm}$ is somewhat larger than expected based on previous work [3]. This enhanced splitting is not understood, but may be due to the increased pump power employed in this work as compared to previous studies of the Stark splitting of this line. 
Because, for the geometry of our Stark laser, the breakdown voltage in methanol reaches a mimimum at a lower pressure than the optimum pressure for submillimeter lasing efficiency, it is necessary to trade-off FIR power for the ability to apply higher fields without breakdown [3]. That is to say, one wants to operate at a pressure which will ensure the most FIR power at a given doublet separation. For the 2 meter laser described in this work, that operating pressure was found to be $170 \mathrm{mT}$ resulting in a doublet separation of $\approx 35 \mathrm{MHz}$. The FIR power achieved at this pressure is $110 \mathrm{~mW}$. At the optimum pressure $(400 \mathrm{mT})$ the maximum power delivered by the laser with no electric field is $215 \mathrm{~mW}$. This trade of power for frequency does not seem too serious a compromise in light of the fact that very reasonable c.w. output power $(110 \mathrm{~mW})$ is achieved at a doublet separation at least an order of magnitude higher than can be achieved by other methods.

Shown in Fig 4 is a beat spectrum as observed with a Schottky diode mixer. The output from the 1 meter long Stark laser was mixed with the output from a standard, unshifted $\mathrm{CH}_{3} \mathrm{OH}$ laser. At an electric field strength of $700 \mathrm{~V} / \mathrm{cm}$ a clear shift of $\approx 14 \mathrm{MHz}$ is observed. The frequency of this beat note was seen to vary roughly linearly as the field strength was shifted over the range of $600-1000 \mathrm{~V} / \mathrm{cm}$. This figure clearly demonstrates that the mode spectrum of the Stark resonator is sufficiently free of transverse modes to allow single frequency operation for the purposes of interferometry. If a second Stark-shifted laser had been available, at least twice as high a beat frequency would have been generated.

At these high pump power levels ( $>50$ Watts ) no clear Stark doublet was observed below $\approx 500-600 \mathrm{~V} / \mathrm{cm}$. This is assumed to be due to the combined effects of power and pressure broadening on the FIR gain curve. The increased bandwidth caused by these effects is also evident in the unshifted cavity scan of Fig 2.

It should also be pointed out that, at the highest pump power, a FIR power enhancement of $10-20 \%$ is seen at low field strength $(\approx 250 \mathrm{~V} / \mathrm{cm})$ due to the non-linear Hanle effect. This effect has been well documented elsewhere [3]. However, at the operating point of Fig 3, no enhancement is expected or observed because the applied electric field is larger than the optimum field for power enhancement.

\section{DISCUSSION}

It has thus been demonstrated that this method can lead to a high modulation frequency while simultaneously delivering high output power. This ability to generate higher modulation frequencies will allow future plasma interferometers to be hardened against fringe loss due to rapid density changes. In addition, increased modulation frequencies will allow much higher data rates to 
be achieved for the study of transierit plasma effects as well as very high frequency plasma modes. As shown in Fig 5 (a) there are other advantages to this technique. This figure shows the standard method of achieving a $1 \mathrm{MHz}$ modulation frequency employed in the present generation of modulated interferometers. With the advent of this high power, Stark-tuned laser it becomes possible to adopt the method shown in Fig 5 (b). In this scheme, the two lasers are tuned to the top of Stark-shifted gain curves rather than on the sides of unshifted gain curves. Thus the output power is not "wasted". In addition, the scheme summarized in Fig 5 (b) should be fundamentally more stable over long periods of time because each laser is operating at the peak of a gain curve rather than on the side. Further, small adjustments can be accomplished with an electric field/voltage change rather than by mechanically changing the cavity length.

Many of the present generation of modulated interferometers employ Schottky diodes as detectors [6]. An additional benefit of using higher modulation frequencies can be realized because at low frequencies $(<1 \mathrm{MHz})$, these diode detectors are limited by $1 / \mathrm{f}$ noise. By increasing the modulation frequency beyond the $1 \mathrm{MHz}$ range, for a fixed power level, the signal to noise ratio should increase as the frequency is increased. 


\section{REFERENCES}

1. S. M. Wolfe, K. J. Button, J. Waldman and D. R. Cohn, "Modulated Submillimeter Laser Interferometer System for Plasma Density Measurements," Appl. Opt. 15, 2645-2648 (1976).

2. D. K. Mansfield, H. K. Park, L. C. Johnson, H. M. Anderson, R. Chouinard, V. S. Foote, C. H. Ma and B. J. Clifton, " Multichannel Far-Infrared Laser Interferometer for Electron Density Measurements on the Tokamak Fusion Test Reactor," Appl. Opt. 26, 4469-4474 (1987).

3. G. Bionducci, M. Inguscio, A. Moretti and F. Strumia, "Design of Molecular FIR Lasers Frequency Tunable by Stark Effect: Electric breakdown of $\mathrm{CH}_{3} \mathrm{OH}, \mathrm{CH}_{3} \mathrm{~F}, \mathrm{CH}_{3} \mathrm{I}$ and $\mathrm{CH}_{3} \mathrm{CN}$," Infrared Phys. 9, 297-308 (1979).

4. D. K. Mansfield, E. Horlbeck, C. L. Bennett and R. Chouinard, "Enhanced, High Power Operation of the 119 um Line of Optically Pumped $\mathrm{CH}_{3} \mathrm{OH}$, "Int. J. Infrared and Millimeter Waves 6, 867-876 (1985).

5. D. T. Hodges, F. B. Foote and R. D. Reel, " Efficient high-power operation of the CW Far-Infrared Waveguide Laser," Appl. Phys. Lett. 29, 662-664 (1976).

6. H. R. Fetterman, P. E. Tannenwald, B. J. Clifton, C. D. Parker, W. D. Fitzgerald and N. R. Erikson, " Far-IR Heterodyne Radiometric Measurements with Quasioptical Schottky Diode Mixers," Appl. Phys. Lett. 33, 151-154 (1978). 
FIGURE CAPTIONS

Fig 1. A cross section of the FIR resonator tube used in this work. Also shown is the orientation of the FIR and pump polarizations.

Fig 2. A cavity scan from the 2 meter Stark laser with no applied field. The cavity modes shown coupled efficiently into $\mathrm{TEM}_{00}$ free space modes.

Fig 3. A cavity scan from the 2 meter Stark laser with the $\mathrm{CH}_{3} \mathrm{OH}$ pressure lowered to allow the application of a $\approx 1 \mathrm{kV} / \mathrm{cm}$ electric field without breakdown. This operating point was chosen as a trade-off between power and doublet splitting. A doublet splitting of $\approx 35$ $\mathrm{MHz}$ is clearly seen at a power level above $100 \mathrm{~mW}$.

Fig 4. A beat spectrum ( $2 \mathrm{MHz} / \mathrm{div}$ ) from the unshifted output from a standard FIR laser mixed with the 1 meter Stark-shifted laser output. A modulation frequency of $\approx 14 \mathrm{MHz}$ is clearly seen. The component at $\approx 1 \mathrm{MHz}$ is from an unwanted transverse mode in the unshifted laser. A Schottky diode was used as the mixer. The laser configuration associated with the measurement is shown in the insert.

Fig 5.(a) The optical method of generating the modulation frequency in the present generation of FIR interferometers. Two lasers (A \& B) are tuned on opposite sides of a narrow gain curve. This technique is limited by the gain bandwidth to frequencies around $1 \mathrm{MHz}$. (b) In this work, the gain curve is Stark-split and the lasers are tuned to the two available peaks. The modulation frequency and long-term stability are thus greatly increased. 
$\frac{\infty}{0}$
$\frac{0}{x}$
$\frac{0}{\#}$
$\frac{1}{0}$
$\frac{0}{a}$

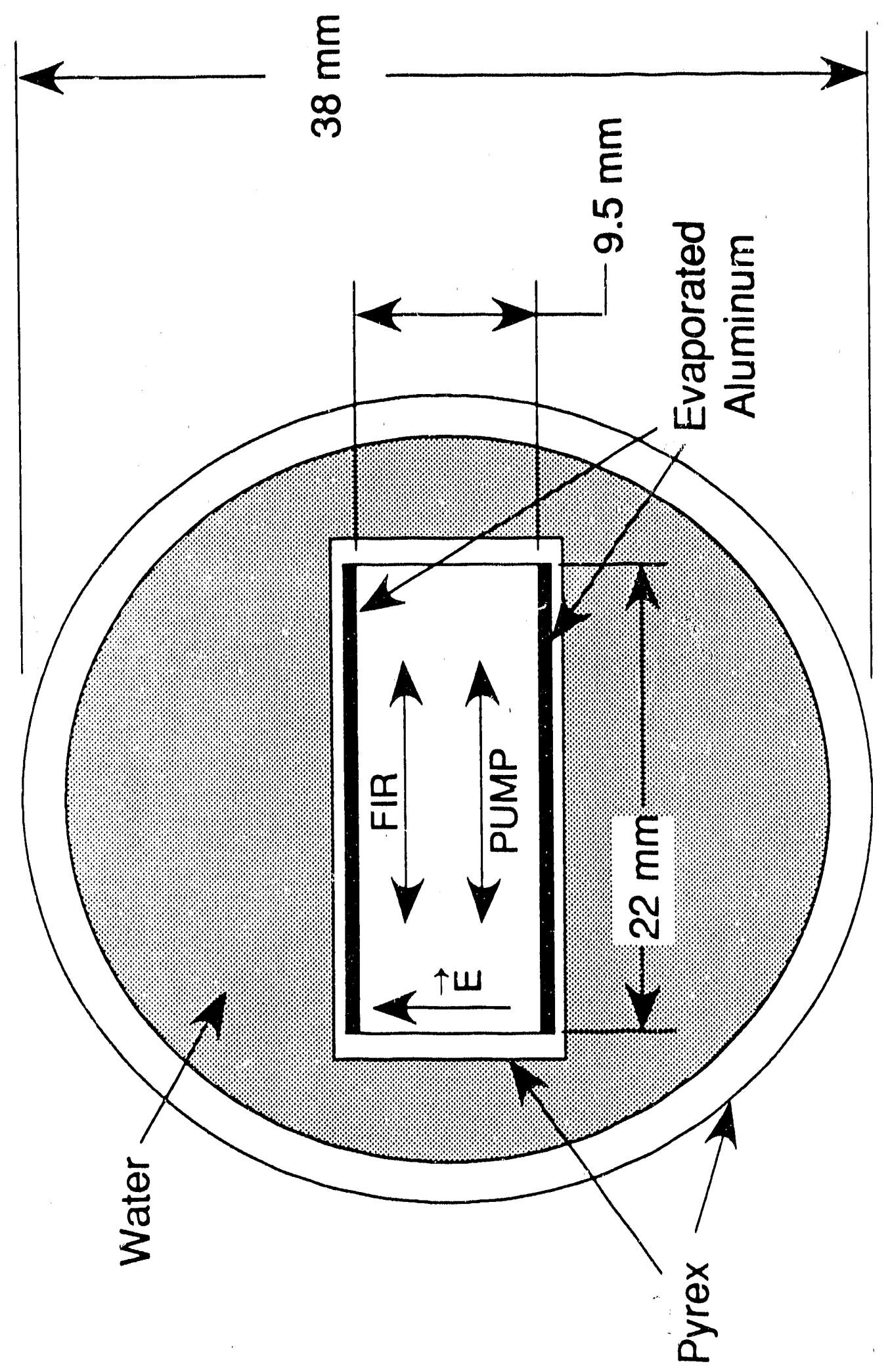

$\underset{0}{-\infty}$ 


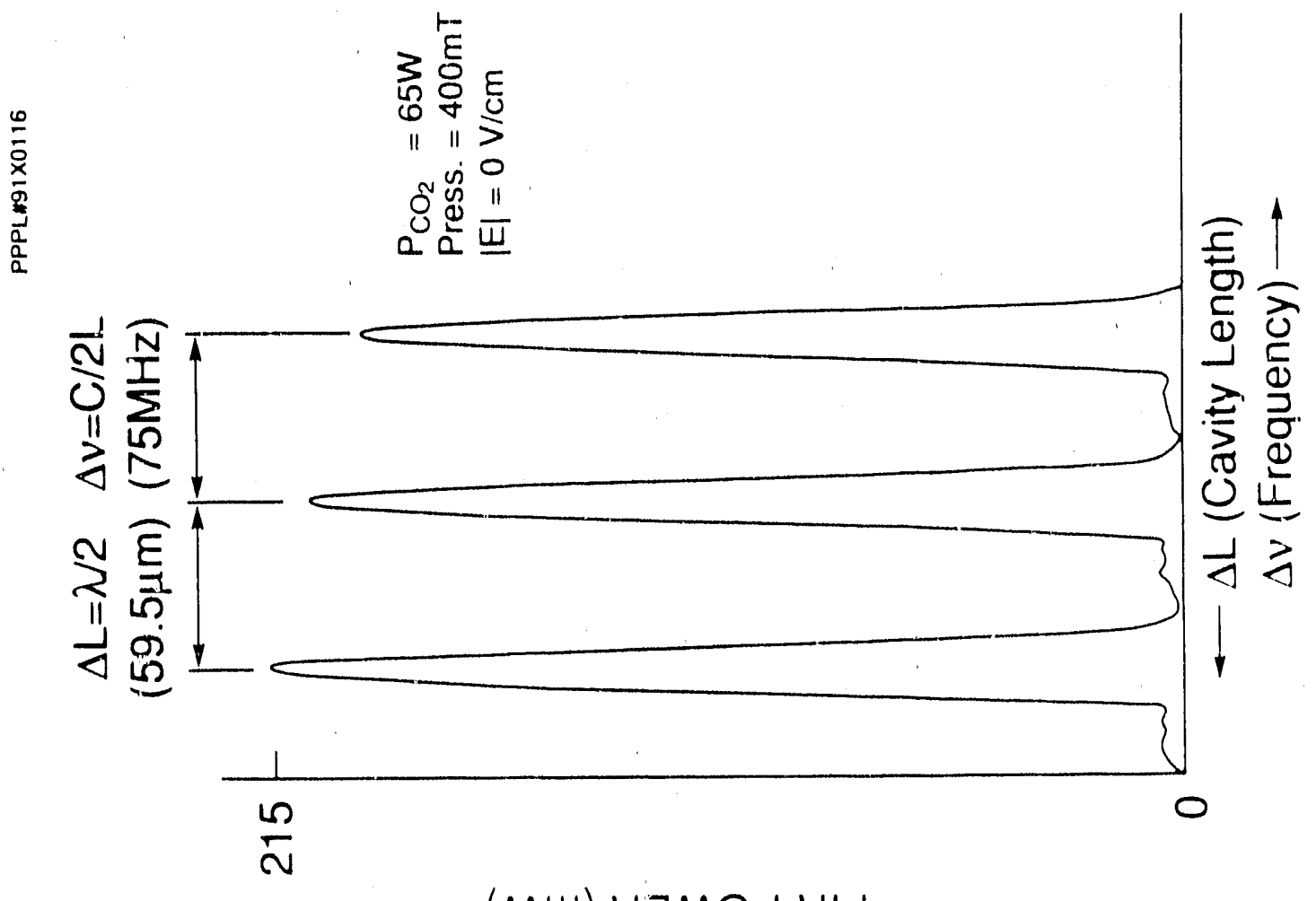

(MW) y 
$\frac{1}{0}$
$\frac{0}{0}$
$\frac{0}{0}$
$\frac{0}{0}$
$\frac{1}{2}$

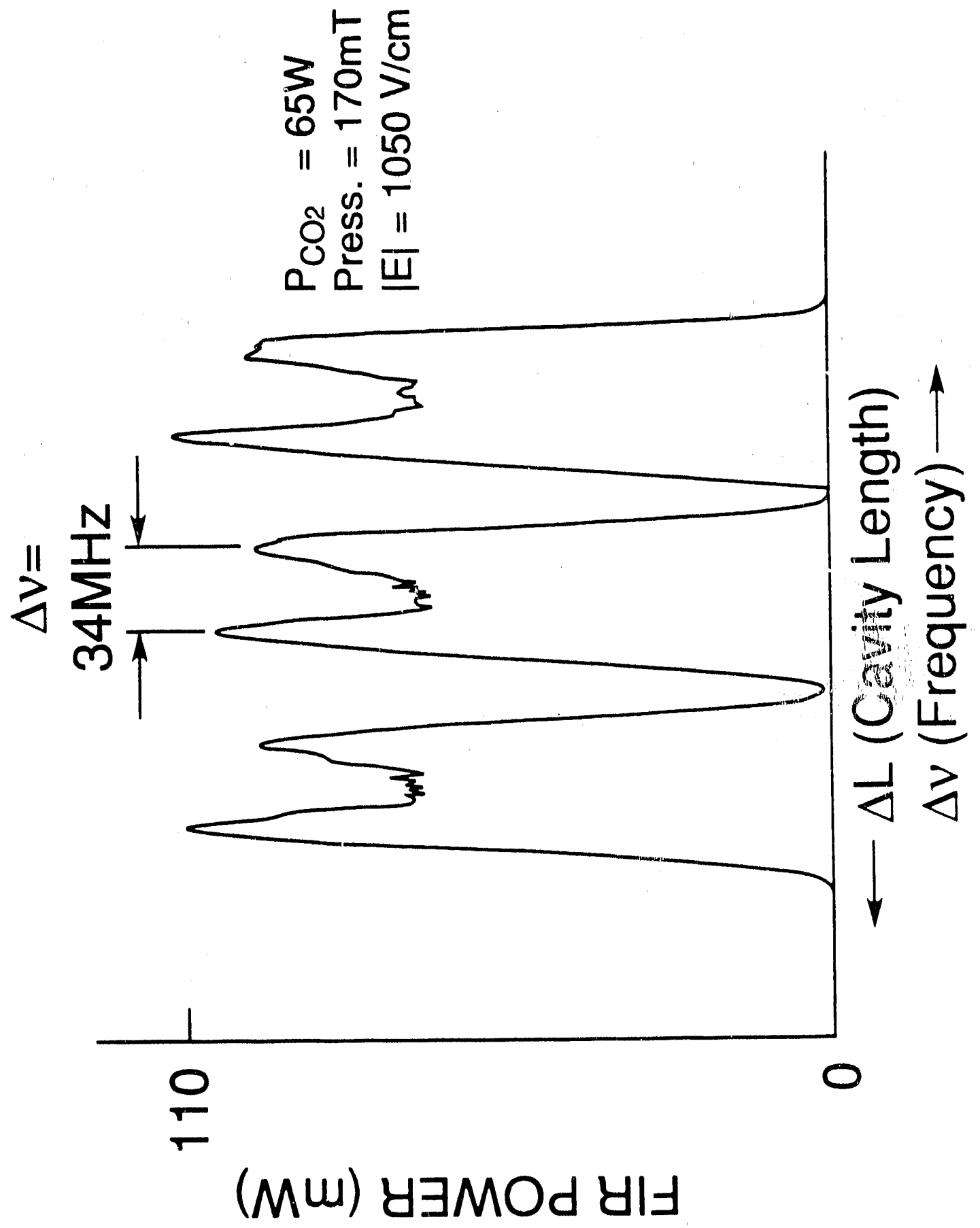




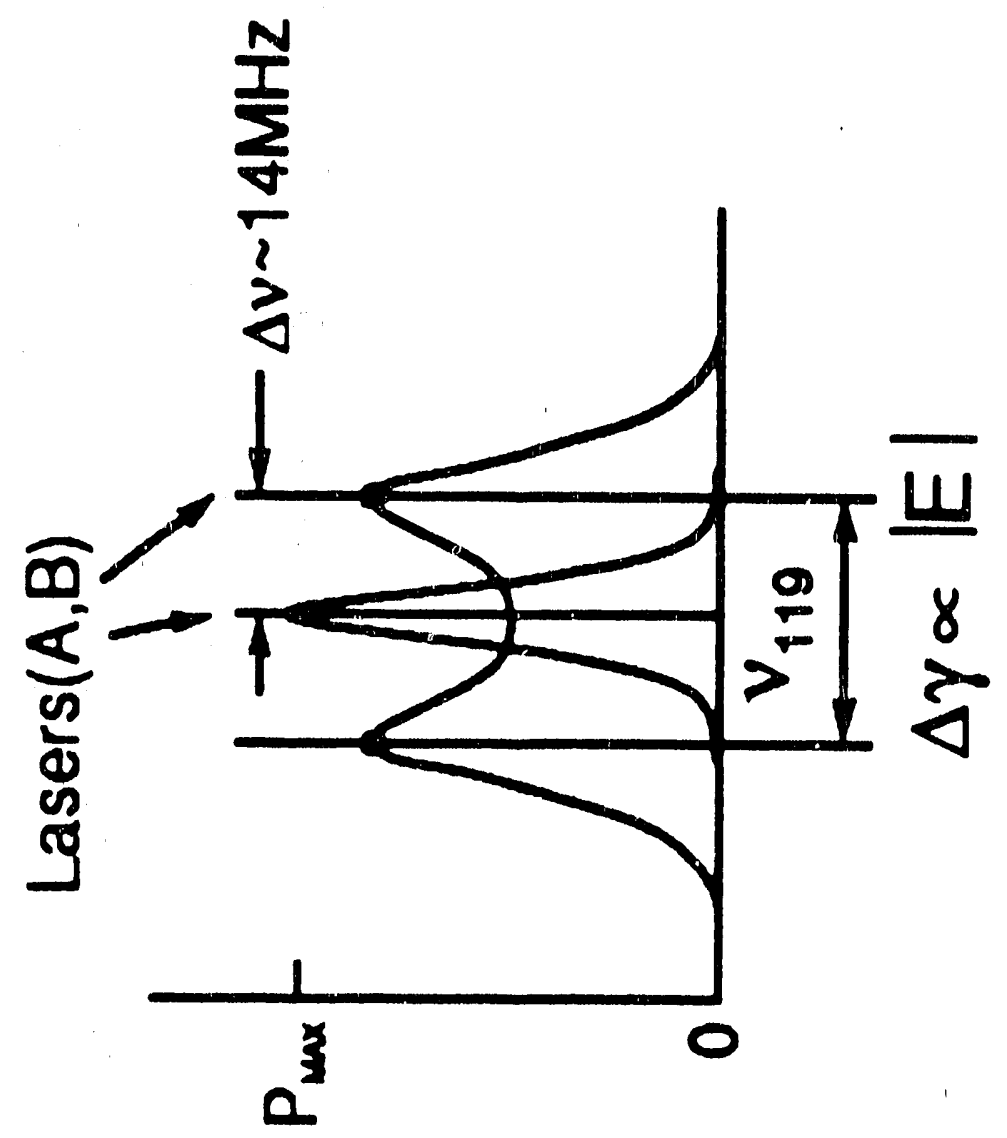

(MW) y

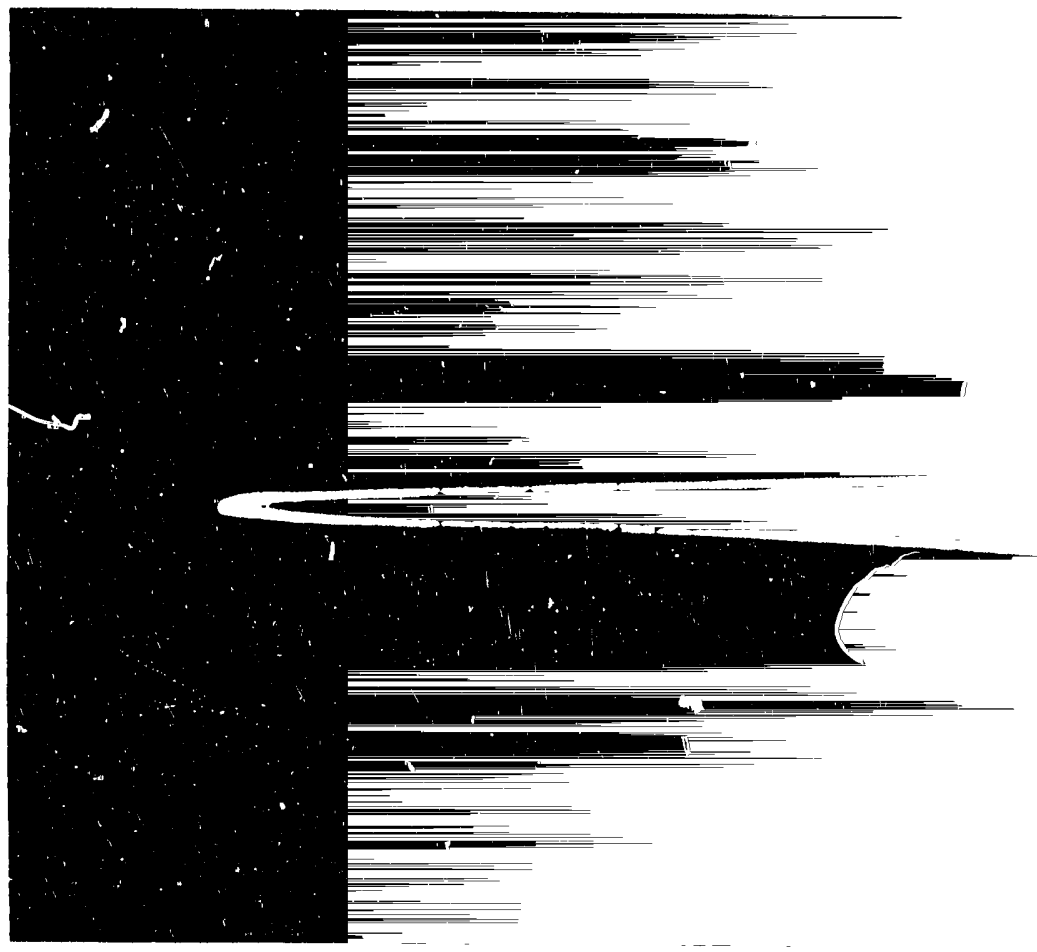




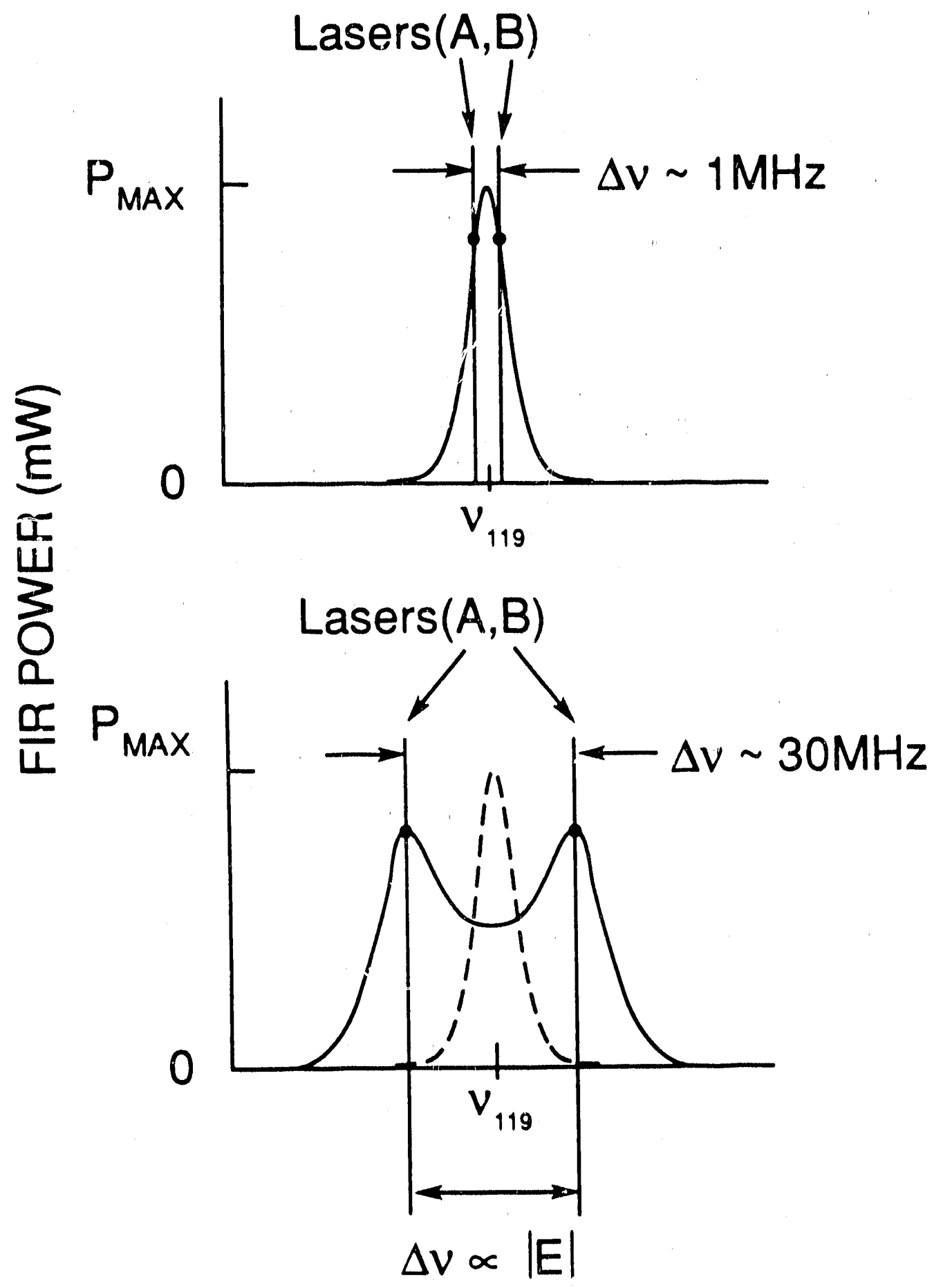

(a)

(b)

Fig. 5 
Dr. F. Peoloni, Univ, of Wollongong, AUSTRALIA

Prof. M.H. Brernan, Univ. of Sydnoy, AUSTRALIA

Plesma Rosearch Lab., Austrelien Nat. Univ., AUSTRALIA

Prot. I.R. Jones, Findors Univ, AJSTRALIA

Prot. F. Cep, Inst for Theoroticel Physics, AUSTRIA

Prot. M. Heinder, Institut far Theoretieche Physik, AUSTRIA

Prot. M. Goosenens, Astronomisch instituUt, BELGIUM

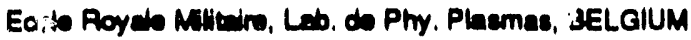

Cominiacion-Europaen, DG. XII-Fusion Prog., BELGIUM

Prof. R. Boudopt, Ripheuriverition Gent, BELGIUM

Dr. P.H. Sakenakn, Instivito Ficica, BRLZIL.

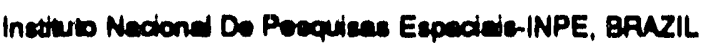

Documentu Ollios, Alomic Energy of Cenada Ldd., CANADA

Dr. M.P. Bectynakd, MPB Technologios, inc., CANADA

Dr. H.M. Skargard, Univ. of Sackutchowen, CANADA

Prol. J. Teichmann, Univ. of Montreal, CANADA

Prot. S.R. Sremivaeen, Univ. of Celogery, CANADA

Prot. T.W. Johnstion, INRS-Energie, CANADA

Dr. A. Botion, Contre canacion de tusion megnotigue, CANADA

Dr. C.F. Jamea." Univ. of Nbert CANADA

Dr. P. Luktic, Komenaktho Univereziti, CZECHOSLOVAKIA

The Librarian, Cuham Leboratory, ENGLAND

Librery, R61, Ruthertord Appleson Laboratory, ENGLAND

Mrs. S.A. Hutchinson, JET Library, ENGLAND

Oy S.C. Shama, Univ. of South Pecific, FIJI ISLANDS

P. Menonen, Univ. of Heleinki, FINLAND

Prot. M.N. Busanc, Ecolo Potyachnique, FRANCE

C. Moutiot, Leb. de Phyaique des Milioux lonieds, FRANCE

J. Radel, CENGCADARACHE - Bat 505, FPUNCE

Prot. E. Economou, Univ. of Crote, GREECE

Me. C. Rinni, Univ. of lowmina, GAEECE

Dr. T. Mud, Acadormy Bibliographic Ser., HONG KONG

Proprint Librery, Hungarian Academy of Sa., HUNGARY

Dr. B. Dascupta, Sahu inst. of Nuclear Physico, INDIA

Dr. P. Kaw, Inss. for Plasma Posearch, INDIA

Dr. P. Rocensu, lereed inst of Technology, ISPAEL

Librerien, Intemational Conter for Theo Physics, ITALY

Miss C. Do Pab, Associaziono EURATOMENEA, ITALY

Dr. G. Groseo, letivubo di Fisica del Plasma, ITALY

Prof. G. Rostemoni, lattaro Gas lonizz;... Dot Cnr, ITALY

Dr. H. Yemeto, Toshiba Res Dowl Center, JAPAN
Prof. I. Kawakemi, Hroshima Univ., JAPAN

Prot. K. Niahikawa, Hiroshima Univ., JAPAN

Director, Jepen Atomic Energy Research Inst., JAPAN

Prot. S. Ioh, Kyushu Univ., JAPAN

Receurch Inio. Ctr., National Instl. for Fusion Scionce, JAPAN

Prot. S. Tonaka, Kyolo Univ., JAPAN

Libreny, Kyoto Univ., JAPAN

Prof. N. Inowe, Univ. of Tokyo, LAPAN

Secretary, Pleama Saction, Electrowathiced Lab., JAPAN

S. Mort, Tectnical Advicor, LAERI, LAPAN

Dr. O. Miderai, Kumamoto inst, of Technobogy, JAPAN

J. Hywon-Sook, Korea Atomic Eneroy Pocearch Inst, KOAEA

D.I. Chai, The Korea Adv. Inst of Sal. Tech., KOREA

Pruf. B.S. Liby, Univ. of Weikab, NEW ZEALAND

Inat of Phyrics, Chinese Aced Sol PEOPLE'S REP. OF CHINA

Librey, Inat. of Plasma Physica, PEOPLE'S REP. OF CHINA

Tinghua Univ. Librery, PEOPLE'S REPUBLIC OF CHINA

Z. Li, S.W. Inat Phyaica, PEOPLE'S REPUBLIC OF CHINA

Prot. J.A.C. Cebrad, Inetituto Superior Tecnioo, PORTUGAL

Dr. O. Potrus, Al I CUzA Univ., ROMANía

Dr. J. do Viliers, Fucion Studies, AEC, S. AFPICA

Prof. M.A. Hewberg, Univ. of Natal, S. AFRICA

Prof. D.E. Xm, Pohang Inat. of Sal. a Tech, SO. KOREA

Prot. C.I.E.M.A.T, Fuation Division Library, SPAIN

Dr. L Sionfio, Univ. of UMEA, SWEDEN

Librery, Royd inet. of Technology, SWEDEN

Prot. H. Whelmoon, Chelmers Univ, of Tech., SWEDEN

Comtre Phys. Des Plasmas, Ecole Polytech, SWITZERLAND

Bibliotheck, Int. Voor Plaemm-Fysica, THE NETHERLANDS

Aset. Prot. Dr. S. Colkir, Niddo East Tech. Univ., TURKEY

Dr. V.A. Gulthikh,Sal. Ree. Inst. Eloctrophys.I Apparatus, USSR

Dr. D.D. Ayuibv, Siberian Brench of Acadomy of Sa., USSA

D. G.A. Eliecen; I.V. Kurchabov Inst, USSR

Librerien, The Uir.SSA Acedemy of Scionces, USSA

Dr. L.M. Kovizhn , th, Inst, of Generd Physics, USSR

Kornforectungaar iege GmbH, Zentrabibliothek, W. GERMANY

Bibliothek, Inst. FOr Plasmatorechung, W. GERMANY

Prot. K. Schinder, Ruhr-Univereitu Bochum, W. GERMANY

Dr. F. Wagner, (ASDEX), Max-Planck-Institut, W. GERMANY

Librerien, Max-Plenck-instiun, W. GERMANY

Prol. P.K. Janov, Inst of Physica, YUGOSLAVIA 

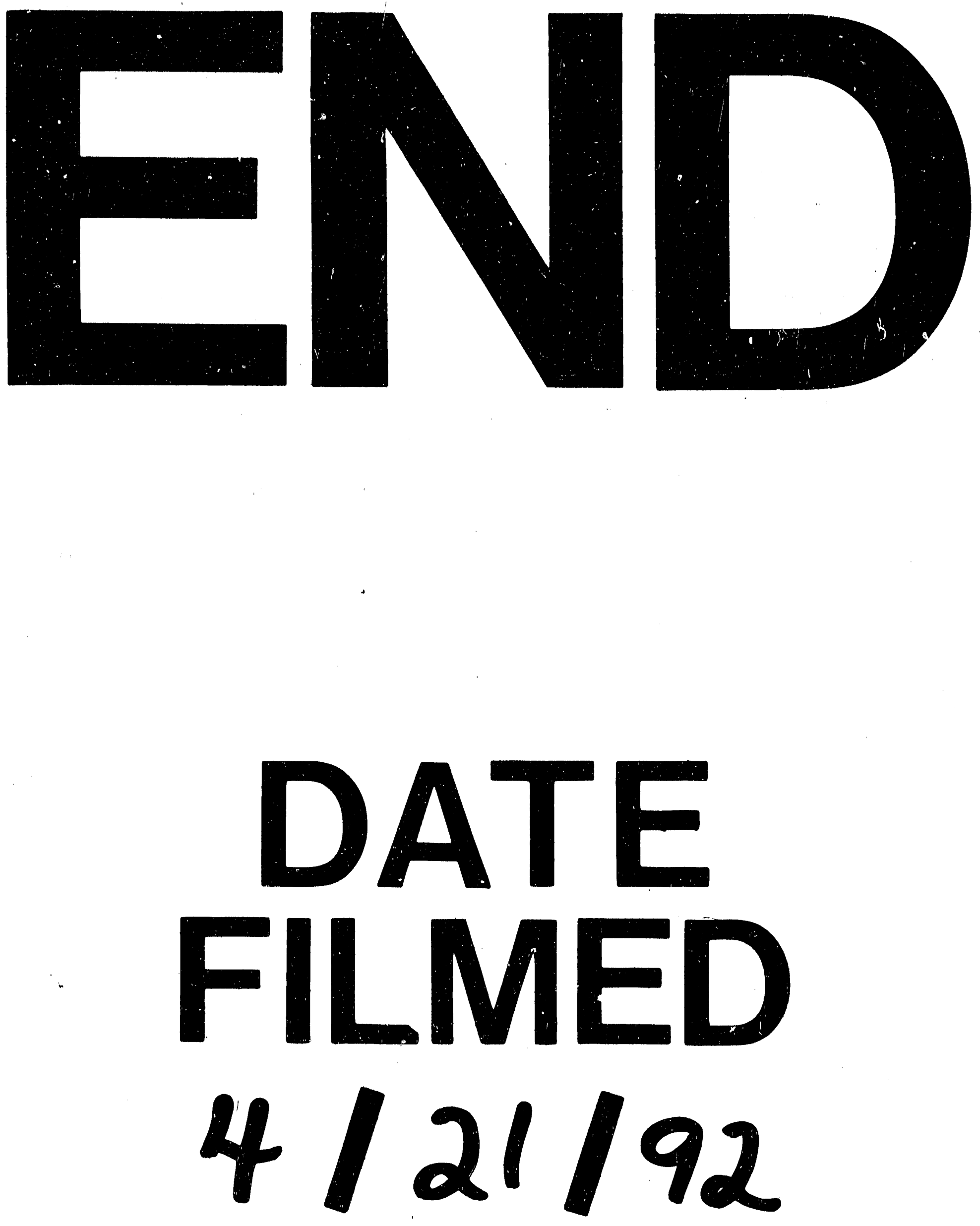
